\title{
Modeling sensitivity of biodiffusion coefficient to seasonal bioturbation
}

\author{
by Pascal Lecroart ${ }^{1,2}$, Sabine Schmidt ${ }^{1}$, Pierre Anschutz ${ }^{1}$ and \\ Jean-Marie Jouanneau ${ }^{2}$
}

\begin{abstract}
Biodiffusion coefficient is the predominant parameter used to constrain biological activity in marine sediments. Bioturbation characterization is important because of the dominant role it plays on the flux determination through the sediment-water interface. Biological mixing is quantified through models of radionuclides diagenesis by both a biodiffusion coefficient (Db) and a mixed depth (L) under the basic steady-state assumption. Based on a new global compilation of radionuclide data in marine sediments and on previously published modeling results, we show that short-live radionuclides are perfectly devoted to quantify biological mixing for sediments associated with $\lambda \mathrm{L}^{2} / \mathrm{Db}$ lower than $125, \lambda$ representing the decay constant of the radionuclide. $75 \%$ of the ${ }^{234} \mathrm{Th}$-derived $\mathrm{Db}$, and $79 \%$ of the ${ }^{7} \mathrm{Be}$-derived $\mathrm{Db}$ are concerned by this result. However, as transient regimes prevail within marine sediments, especially at a seasonal time scale and within the coastal and shelf environment, it is necessary to model their impacts on Db calculations. A transient model of radionuclide decay and transport is therefore used to perform extensive sensitivity tests of $\mathrm{Db}$ calculations in respect to seasonal mixing. Numerical tests of seasonal sensitivity indicate that ${ }^{234} \mathrm{Th}$ and ${ }^{7} \mathrm{Be}$ are the most sensitive tracers to seasonal biological mixing: the steady-state assumption remains valid and applicable for most of natural marine environments. However, systematic tests reveal that incorrect seasonal sensitivity of ${ }^{234} \mathrm{Th}$ is detected for marine environments with $\lambda \mathrm{L}^{2} / \mathrm{Db}$ lower than 10 and greater than 1000. In these cases, the apparent seasonal variations of the biological activity need to be corrected. The main parameter in selecting the appropriate radionuclide for field analyses is the dimensionless pulse, which defines the relative importance of decay time scale relative to the seasonal time scale. This pulse controls the relative extension of the domain of satisfactory sensitivity. Consequently, long-lived radionuclides $\left({ }^{210} \mathrm{~Pb}\right.$ and $\left.{ }^{228} \mathrm{Th}\right)$ are not appropriate for predicting seasonal mixing, except for specific environments which display an unexpected sensitivity to seasonal mixing. These marine environments are characterized by a moderate biological mixing and a deep mixed-layer.
\end{abstract}

\section{Introduction}

Bioturbation is defined by the mixing of surface sediments by organism activity, which can introduce significant modifications to the physical, biological and chemical properties of sediment. Bioturbation can redistribute particles within the surface layer of marine

1. Université Bordeaux 1, CNRS, UMR 5805-EPOC, Avenue des Facultes, Talence F-33405, France.

2. Corresponding author.email:p.lecroart@epoc.u-bordeau1.fr 
sediments, dispersing the stratigraphic record (Ruddiman and Glove, 1972; Guinasso and Schink, 1975; Wheatcroft, 1990) and influence the spatial extent of the different reactions of organic matter mineralization. Through the redistributing reactive particles, bioturbation can significantly affect the gradients of pore-water constituents and consequently their fluxes across the sediment-water interface (e.g. Schink and Guinasso, 1977). Bioturbation can accelerate pollutant burial or, inversely, remobilization of buried contaminants (e.g. Bosworth and Thibodeaux, 1990). In the absence of physical sediment reworking, i.e. currents, bioturbation constitutes the major process affecting sedimentary particles. Therefore, quantification of the biological mixing rates is fundamental. The most widely used mathematical method to evaluate bioturbation is based on the analogy of eddy diffusion for which the biological mixing is characterized by both a biodiffusion coefficient $(\mathrm{Db})$ and a mixed depth (L) (Goldberg and Koide, 1962; Guinasso and Schink, 1975; Berner, 1980; Aller, 1982; Boudreau, 1997). Extensive developments concerning the conditions of this biodiffusive approach were exposed by Meysman et al. (2003) who concluded that biodiffusion has proven to be a valuable empirical model for sediment mixing. Recently, Reed et al. (2006) suggested that short-lived radionuclides are not suitable to be used with the biodiffusive model. This analysis will be discussed later. The biodiffusion parameters are commonly estimated by modeling depth profiles of naturally occurring or anthropogenic radionuclides added to the sediment in association with fine-grained particles. Naturally occurring radionuclides, such as ${ }^{234} \mathrm{Th},{ }^{7} \mathrm{Be},{ }^{228} \mathrm{Th}$ or ${ }^{210} \mathrm{~Pb}$ are commonly used to calculate the biodiffusion coefficient. Their half-life extends from 24.1 day $\left({ }^{234} \mathrm{Th}\right)$ to 22.3 year $\left({ }^{210} \mathrm{~Pb}\right)$. The $\mathrm{Db}$ calculation from natural radionuclides-depth profiles is based on the steady-state approximation that stipulates the lack of time variations of both biological activity and radionuclide flux through the sediment-water interface. However, detailed examinations of natural sedimentary environments exhibit strong temporal variations related to a number of variables, i.e.(i) Seasonal biological activity, (ii) Meteorological conditions and (iii) Transient flux of matter through the sediment-water interface (e.g. Martin and Bender, 1988; Sun et al., 1991; Soetaert et al., 1996a; Gerino et al., 1998; Schmidt et al., 2002, 2006). Many authors have extensively discussed conditions of steady-state application (see review in Boudreau, 1997, p. 191) and concluded that transient-state regimes are the rule in the marine sediments instead of the exception. Moreover, the steady-state approximation remains valid, firstly, when fluctuations imposed on the system have a mean period significantly shorter than the other process-time scales and, secondly, when fluctuations exhibit longer periodicity than the other process-time scales. In these cases, a sedimentary system can be described by a series of steady-states (Boudreau, 1997). Transient regime can exert significant perturbations on the Db calculation process. For example, using a diagenetic model of short-lived radionuclides, Lecroart et al. (2007) have shown that the transient regime imposed by variations of radionuclide flux to the sediment-water interface can generate significant error (up to a factor of two) upon the calculation of the $\mathrm{Db}$ coefficient.

Due to the few studies that deal with bioturbation variations in marine environments 
Table 1

$\begin{array}{cccc} & & \text { Decay constant } & \text { Pulse } \\ \mathrm{Db} \text { tracer } & \text { Half-live } & \lambda\left(\mathrm{y}^{-1}\right) & \gamma \\ { }^{234} \mathrm{Th} & 24.1 \mathrm{~d} & 10.51 & 0.095 \\ { }^{7} \mathrm{Be} & 53.3 \mathrm{~d} & 4.75 & 0.211 \\ { }^{228} \mathrm{Th} & 1.9 \mathrm{y} & 0.365 & 2.74 \\ { }^{210} \mathrm{~Pb} & 22.3 \mathrm{y} & 0.0311 & 31.74\end{array}$

(e.g. Gerino et al., 1998; Schmidt et al., 2007), the literature has not explored, up to now, the sensitivity of the biodiffusion coefficient to seasonal biological activity. Therefore, a modeling approach is clearly required to solve this problem. We used a non-steady-state and dimensionless model of radionuclide diagenesis to test the sensitivity of the $\mathrm{Db}$ calculation scheme to seasonal variations of biological activity. This model simulates transient tracer profiles affected by seasonal bioturbation. This study precisely characterizes how the traditional method, used to compute $\mathrm{Db}$, is able to follow the transient biological activity. This work is particularly relevant for the natural radionuclides traditionally used to constrained biodiffusion coefficient (Table 1), which are divided into two classes: the short-lived radionuclides $\left({ }^{224} \mathrm{Th}\right.$ and $\left.{ }^{7} \mathrm{Be}\right)$ and the long-lived ones $\left({ }^{228} \mathrm{Th}\right.$ and ${ }^{210} \mathrm{~Pb}$ ).

\section{Model equations and numerical solution}

\section{a. Model equation}

Bioturbation is classically described as an eddy-diffusive transport process occurring within a surface mixed layer (Goldberg and Koide, 1962). Biodiffusion is a local transport associated with spatially random and small scale sediment displacements between each mixing event (Boudreau, 1986a; Meysman et al., 2003). Nonlocal mixing, which implies exchange of material between non-adjacent points, exists in natural environments (Boudreau, 1986b). Biodiffusion and non-local mixing are generally treated separately. This study is only concerned by radionuclides sensitive to seasonal biodiffusive mixing events, but does not assess their sensitivity to nonlocal bioturbation. Consequently, complementary field investigations and modeling studies are needed to address this additional problem.

Surface sediments are characterized in one dimension by a mixed layer of thickness L with a constant porosity. The classical advection-diffusion model equation adapted for radionuclides is

$$
\frac{\partial A}{\partial t}=\operatorname{Db}(t) \frac{\partial^{2} A}{\partial z^{2}}-\mathrm{w} \frac{\partial A}{\partial z}-\lambda A
$$

where $A$ is the activity of the radionuclide within the mixed layer, $z$ the depth in the mixed layer relative to the sediment-water interface, $\mathrm{Db}$ the biodiffusion coefficient, $\mathrm{w}$ the burial 
rate, and $\lambda$ the decay rate of considered radionuclide (Table 1). By assuming steady-state, Eq. (1) can be solved and Db computed

$$
\mathrm{Db}=\frac{\lambda z^{2}}{\left(\ln \left(A_{0} / A_{z}\right)\right)^{2}}-\frac{\mathrm{w} z}{\ln \left(A_{0} / A_{z}\right)}
$$

$\mathrm{Db}$ is then characterized from depth profiles of radionuclide activity measured in the sediment cores. In field investigations, steady-state approximation is often validated by the observation of a significant correlation between the logarithm of the radioisotope activity and the depth. This analysis is not always sufficient because transient profiles can easily mimic steady-state ones in a semi-logarithm diagram (Lecroart et al., 2007). However, when transient biodiffusion occurs, the computed $\mathrm{Db}$ does not only characterize the biological activity just before core extraction, but integrates also past bioturbation variations. In this study, several seasonal variations are imposed to the biodiffusion coefficient. The advection-diffusion model Eq. (1) is used to calculate the apparent $\mathrm{Db}$ (Eq. 2 ), which is compared to the expected one initially introduced into the model. Negligible difference between the apparent and the expected values implies that the selected radionuclide is perfectly adapted to follow seasonal biological activity. The close comparison of the transient profile with the steady-state one is regularly examined. This condition is necessary to adopt the classical $\mathrm{Db}$ calculation.

The temporal dependence of biodiffusion is approached by an input function of prescribed sine shape

$$
\mathrm{Db}(t)=\mathrm{Db}_{\mathrm{m}}\left(1-\frac{\alpha}{100} \sin (2 \pi t / \mathrm{T})\right)
$$

where $\mathrm{T}$ represents the period of biological oscillations, $\alpha$ the oscillation amplitude, and $\mathrm{Db}_{\mathrm{m}}$ the mean value of the biodiffusion coefficient. The use of a different function shape gives similar results for comparable input parameters.

Eq. (1) is simplified by introducing dimensionless variables (Guinasso and Schink, 1975 and Boudreau, 1986a). This transformation proposes a more general approach, reducing the number of free tested parameters and correlatively the number of simulations needed to be performed. Therefore, Boudreau's (1986a) approach to make Eq. (1) dimensionless was followed except for the dimensionless time variable which is expressed relative to the decay rate i.e. $\tau=\lambda t$. In transient study, it is intuitive that sensitivity may depend on the decay rate of the radionuclide. Sensitivity of biodiffusion to seasonal mixing is dominated by the balance between biodiffusion and radioactive decay. Other choices are possible depending on the objects of the study. For example, Boudreau (1986a) expressed time variable relative to the characteristic diffusion time to test the influence of the depth distribution of benthic infaunal organisms within the mixed layer. According to dimensionless approach, Eq. (1) becomes

$$
\operatorname{Da} \frac{\partial \theta}{\partial \tau}(\varepsilon, \tau)=\mathrm{f}(\tau) \frac{\partial^{2} \theta}{\partial \varepsilon^{2}}-\operatorname{Pe} \frac{\partial \theta}{\partial \varepsilon}-\operatorname{Da} \theta
$$


where $\theta$ is the dimensionless activity defined by dividing $A$ by the initial activity at the sediment-water interface, $\varepsilon$ is the nondimensional depth, that is $\varepsilon=z / \mathrm{L}$. Pe and $\mathrm{Da}$ are the dimensionless Peclet and First Damkohler numbers, respectively (see details in Boudreau, 1986a).

$$
\begin{aligned}
& \mathrm{Pe}=\mathrm{wL} / \mathrm{Db}_{\mathrm{m}} \\
& \mathrm{Da}=\lambda \mathrm{L}^{2} / \mathrm{Db}_{\mathrm{m}}
\end{aligned}
$$

Pe defines the relative influence of burial on biodiffusion in surficial sediments. For example, sediment environment with large Pe value are particularly relevant for the burial of paleoceanographic signal. Da measures the relative influence of decay compared to biodiffusion. Perfect radionuclide is characterized by a decay characteristic time $(1 / \lambda)$ as close as possible to the biodiffusion time $\left(\mathrm{L}^{2} / \mathrm{Db} \mathrm{m}_{\mathrm{m}}\right)$ that means $\mathrm{Da}$ is close to 1 . The confidence level around 1 is not as restricted as predicted by the theory (see discussion). Excessive decay rates imply that the radionuclide is only detectable in a narrow part of the mixed-layer. Db calculation will be imprecise. Inversely, radionuclides associated with reduced decay rates generate homogeneous radioactive profiles in the mixed-layer. Decay is insufficient relative to biodiffusion to exhibit a radioactive decrease with depth. The classical procedure adopted to compute Db is not relevant in this case. $\mathrm{f}$ in Eq. (4) is the dimensionless biodiffusion function defined by

$$
\mathrm{f}(\tau)=1-\frac{\alpha}{100} \sin (2 \pi \gamma \tau)
$$

where $\gamma$ is the dimensionless pulse defined by $\gamma=1 / \lambda \mathrm{T}$. $\gamma$ characterizes the importance of the decay period of the tracer relative to the period of the biodiffusion variations (Table 1). Dimensionless approach reduces the number of free parameters from six with the dimensional equation ( $w, \alpha, \mathrm{Db}_{\mathrm{m}}, \mathrm{L}, \mathrm{T}, \lambda$ ) to four ( $\left.\mathrm{Pe}, \mathrm{Da}, \alpha, \gamma\right)$.

\section{b. Boundaries and initial conditions}

The boundary condition at the sediment-water interface $(\varepsilon=0)$ is a fixed flux condition

$$
\psi=\operatorname{Pe} \theta-\mathrm{f}(\tau) \frac{\partial \theta}{\partial \varepsilon}
$$

$\psi$ is the dimensionless radionuclide flux to the sediment. For convenience, $\psi$ was fixed to 1 which did not affect the results of this study. Boundary condition at the base of the bioturbated layer $(\varepsilon=1)$ is a no gradient condition. Biodiffusion theory assumes a semi-infinite mixed layer with a no-gradient boundary condition at the base of the bioturbated layer. In the classical papers, which deal with modeling of bioturbation with radionuclides (e.g. Boudreau, 1986a; Reed et al., 2006; Meysman et al., 2007), the mixed-layer depth is fixed. This choice is justified for short-lived radionuclides that do not reached the base of the bioturbated layer. This assumption is only acceptable for the two 
long-lived radionuclides that reach the base of the bioturbated layer, (see details in Reed et al; 2006). The error introduced by this assumption is negligible for ${ }^{228} \mathrm{Th}$ and ${ }^{210} \mathrm{~Pb}$.

The initial condition is defined by the analytical steady-state solution of Eq. (4) with $\mathrm{f}(\tau)=1$ (formulae derived from the literature, e.g. Boudreau, 1997). These conditions are classically encountered in modeling studies of diagenesis.

\section{c. Model resolution and apparent biodiffusion function calculation}

Eq. (4) is solved using a finite element approach implemented with the PDE Modes module of COMSOL Multiphysics ${ }^{\circledR}$. The simulation output consists of depth profiles of radioactive tracers affected by seasonal biological activity. Space step is fixed to $1 / 30$ of the mixed layer. Depth profiles are computed during a five-year period of time with a time step of 1/16 year. In dimensionless analysis, these parameters correspond with a time scale included between 0 and $5 \lambda$ and a $\lambda / 16$ time step. From each simulated profile, the apparent biodiffusion function $\left(f_{a p p}\right)$ is computed using the following dimensionless formula:

$$
\mathrm{f}_{\text {app }}(\tau)=\frac{\mathrm{Da}}{s l^{2}}+\frac{\mathrm{Pe}}{s l}
$$

$s l$ defines the slope of the profile in a semi logarithmic diagram. The standard approach is justified by the similarity between transient and steady-state solutions of Eq. (4). It is clear that detection of transient state is extremely difficult to visualize from measured radioactive profiles in the case of marine sediments dominated by biological activity. Validity of the linear regression that results to the steady-state assumption is nevertheless continuously checked by calculating the correlation coefficient between the logarithm of the activity and the depth along the profile. The length of the profile selected to compute biodiffusion function is defined by the distance between the sediment water interface and the depth for which radioisotope activity is equal to $1 / 10$ of that observed at the sediment-water interface. When the tracer reaches the base of the bioturbated layer, the top half of the bioturbated layer is only considered to compute the apparent biodiffusion function. This process minimizes the influence of the boundary condition at the base of the system. For profiles with insignificant correlation (99 percent confidence level), the length of the profile is reduced in order to try to obtain a more significant correlation. When the distance becomes too small (lower than $1 / 10$ of the mixed-layer depth), the profile is excluded.

Relative difference between $\mathrm{f}_{\text {app }}$ and $\mathrm{f}$, initially introduced into the model, is explained by insufficient sensitivity of the tracer to seasonal biological mixing. The sensitivity is then quantitatively defined by

$$
\mathrm{S}=\alpha_{\text {app }} / \alpha
$$

$\alpha_{\text {app }}$ is the apparent amplitude of the temporal variations of the biodiffusion function. Perfect sensitivity of the radionuclide to seasonal mixing implies $\mathrm{S}=1$ whereas insensitivity is associated with $S=0$. Overestimation (under) of seasonal bioturbation is related to $\mathrm{S}>1$ ( $\mathrm{S}<1$, respectively). 


\section{Pe and Da within marine surface sediments}

Prior to performing time-expensive simulations, it is pertinent to determine the actual range of $\mathrm{Pe}$ and $\mathrm{Da}$ variations in natural environments. To do that, computed $\mathrm{Pe}$ and $\mathrm{Da}$ values are obtained from a comprehensive database of transport parameters ( $\mathrm{Db}, \mathrm{w}$ and $\mathrm{L}$ ) reported in the literature. This compilation is based on existing ones extracted from previously published papers (Boudreau, 1994; OMEX database, van Weering et al., 1998; Middelburg et al., 1997; Smith and Rabouille, 2002) updated with recently published data (references in Table 2). Biodiffusion coefficient was calculated from depth profiles of ${ }^{210} \mathrm{~Pb},{ }^{228} \mathrm{Th},{ }^{7} \mathrm{Be}$ or ${ }^{234} \mathrm{Th}$ assuming validity of both the diffusion-advection model and the steady-state approximation. The mixed-layer depth is extracted from literature or directly determined from published ${ }^{210} \mathrm{~Pb}$ depth profiles. In this later case, mixed-layer depth is defined either as the depth of the maximum radionuclide penetration for deep-sea environments associated with small burial rate or, for shelf or coastal environments, as the depth of the strong slope break-up observed along the radioactive profile. Published burial velocities were computed from the long-lived radionuclides $\left({ }^{210} \mathrm{~Pb}\right.$ and $\left.{ }^{14} \mathrm{C}\right)$. This new compilation offers a comprehensive characterization of transport processes extracted from 387 sediment cores. Database encompasses coastal to deep-sea environments (water-depth ranging from 0 to 5654 meters) with an uneven geographical distribution that depends on either the half-life of the radionuclide, or the proximity of marine research laboratories (Table 2 and Fig. 1). ${ }^{7} \mathrm{Be}$ is only detectable in the shallowest marine sedimentary environment and the Southern hemisphere is poorly constrained. Pe and Da display ranges of five and six magnitude orders, respectively. The range of mixed layer depth is more restricted (from $1 \mathrm{~cm}$ to $41 \mathrm{~cm}$, Table 2). So, for a given radioisotope, Pe and Da variations are mainly controlled by $\mathrm{Db}$ and w variations.

A convenient way to illustrate the relative importance of transport and decay processes in surficial sediment is to plot the two dimensionless parameters $\mathrm{Pe}$ and $\mathrm{Da}$ in a logarithmic diagram (Fig. 2 a, b, c). Four sectors can be defined by the lines $\mathrm{Pe}=1$ and $\mathrm{Da}=1$. The top left-hand sector (sector 1) corresponds with marine sediments dominated by bioturbation over burial. In this sector, the tracer decay presents a time scale larger than the bioturbation time scale. For convenience, we have chosen the long-lived ${ }^{210} \mathrm{~Pb}$ radioisotope to illustrate the influence of the parameters Pe and $\mathrm{Da}$ on the shape of the depth profile of radioisotope. The tracer profiles can be modelled with a simple steady-state model of diagenesis that has two layers, the upper one affected by biodiffusion and burial and the lower one by burial only. Biodiffusion coefficient, burial rate and porosity are assumed to be constant. In this simple case, an analytical solution exists for the diagenetic equation. Formulae are derived from the literature (e.g. Boudreau, 1997). In sedimentary environments located within sector 1, the tracer-depth profile presents a clear decrease in the mixed layer and a strong slope break-up located at the base of the mixed layer (Fig. 3a). In this sector, Db and L determination process is robust. In sector 1 , short-lived radioisotopes display rapid decay that generally inhibits their penetration beneath the mixed layer. The majority of points associated with ${ }^{234} \mathrm{Th}$ falls inside this sector. On the other hand, the sector 2 characterizes 


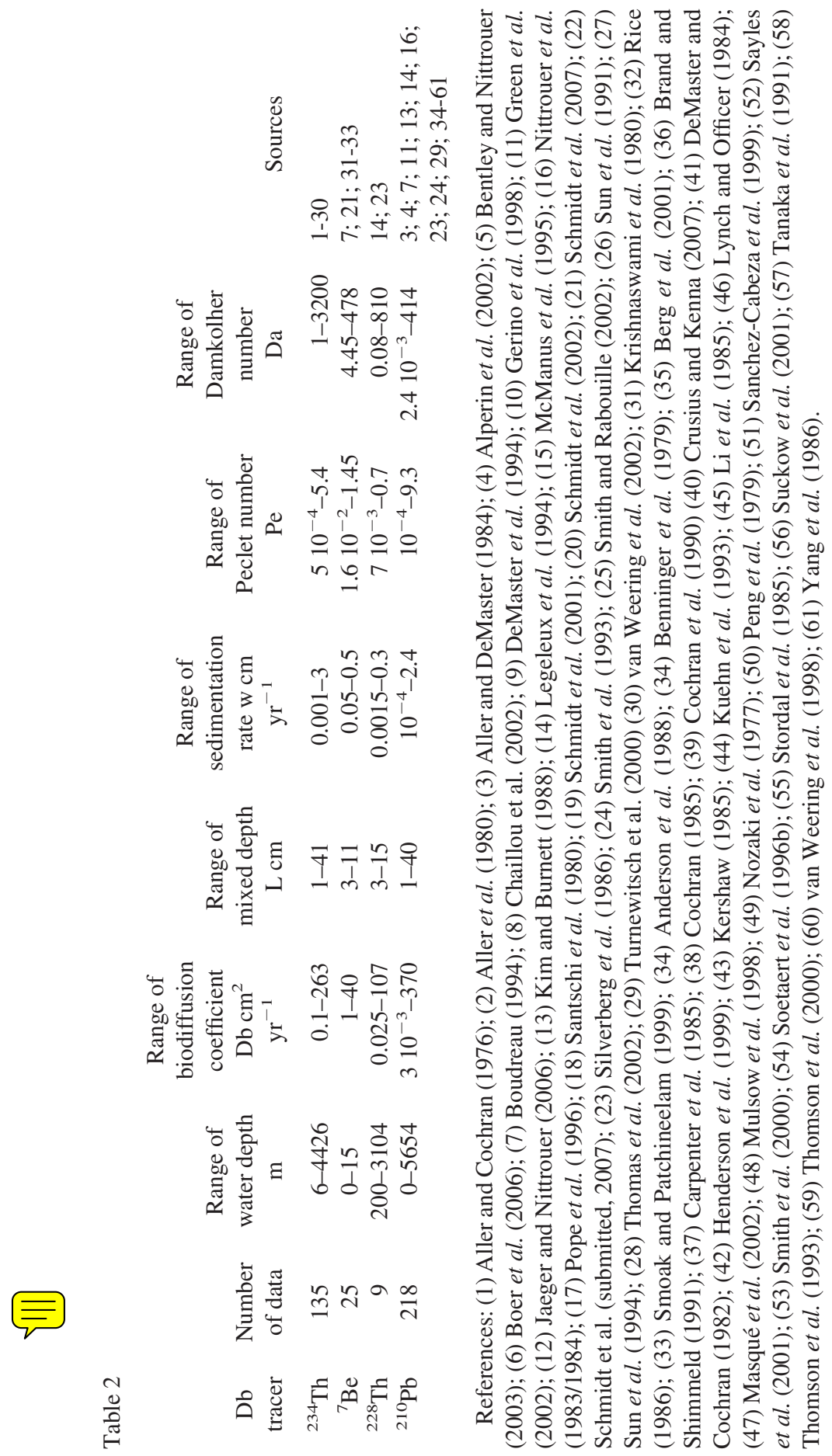


a)

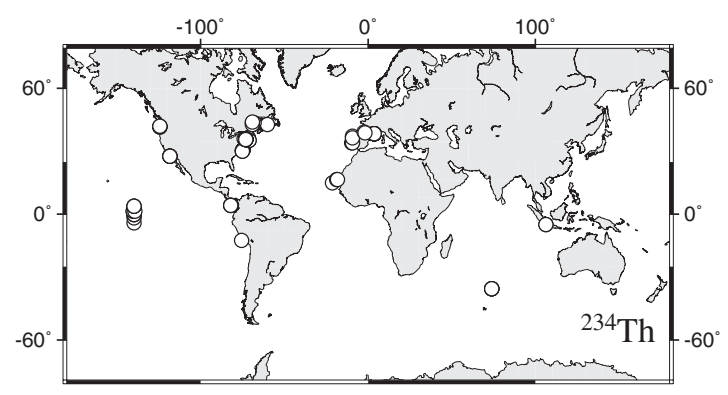

b)

c)
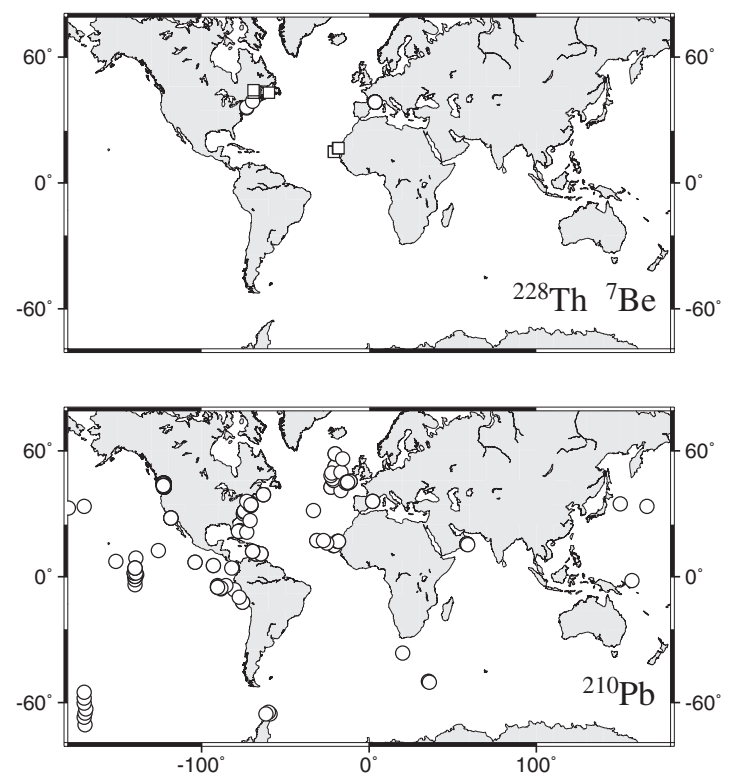

Figure 1. Location map of the sites where a comprehensive description of surficial sediment transport parameters exists. Db values were characterized from (a) ${ }^{234} \mathrm{Th}$ profiles, (b) ${ }^{7} \mathrm{Be}$ (circles) or ${ }^{228} \mathrm{Th}$ profiles (square) and (b) from ${ }^{210} \mathrm{~Pb}$ profiles.

natural sediments in which bioturbation dominates both the burial and decay processes. In this case, the mixed layer depth does not display significant radioactive decrease and $\mathrm{Db}$ calculation can be submitted to uncertainty due to profile slope inaccuracy (Fig. 3b). Most of the ${ }^{210} \mathrm{~Pb}$ points fall inside the sector 1 but a significant quantity is located within sector 2. However, caution must be taken for Db calculation from the smaller $\mathrm{Da}$ values located within the sector 2. Sector 3 is associated with sediment dominated by burial relative to biodiffusion. Decay time scale dominates biodiffusion time scale and consequently, radioactive profiles can display significant break-up at the base of the mixed layer (Fig. 3c). $\mathrm{Db}$ and $\mathrm{L}$ determination are thus subjected to caution because of the predominant burial processes. In natural sedimentary environments, this caution only concerns a few ${ }^{210} \mathrm{~Pb}-\mathrm{Db}$ 
a)

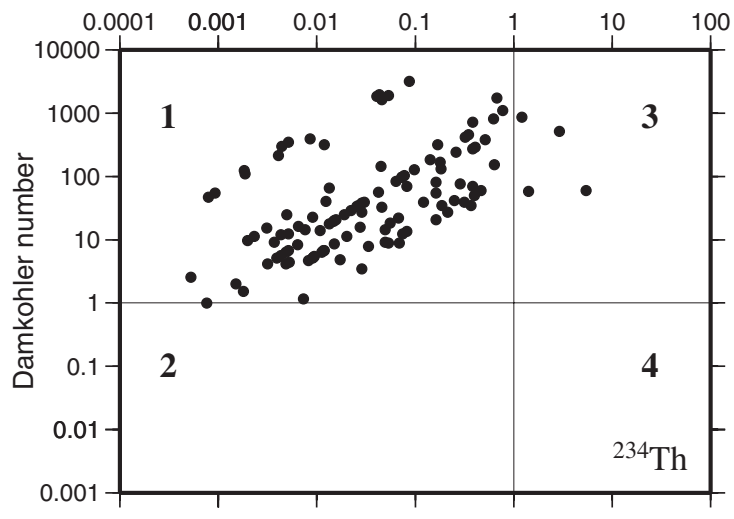

b)

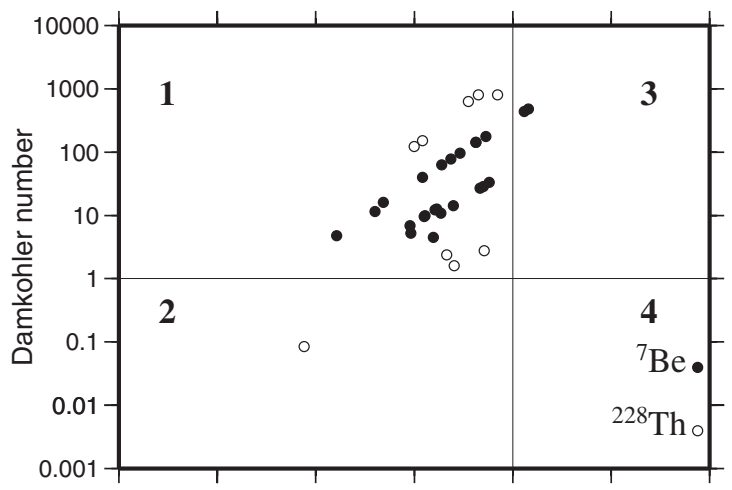

c)

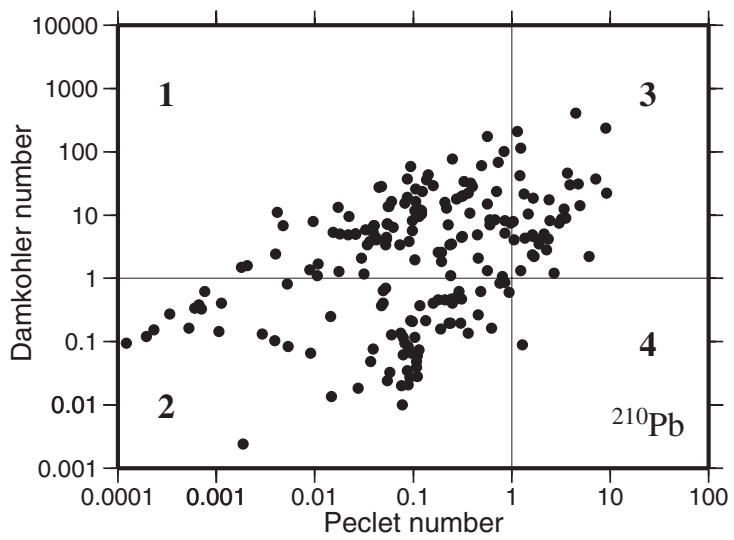

Figure 2. Peclet number versus Damkohler number for the different surficial sediment sites. Db used to the dimensionless analysis is obtained from (a) ${ }^{234} \mathrm{Th}$ profiles, (b) ${ }^{7} \mathrm{Be}$ (close circles) or ${ }^{228} \mathrm{Th}$ (open circles) and (c) ${ }^{210} \mathrm{~Pb}$ profiles. See text for the signification of the four sectors. 
a)

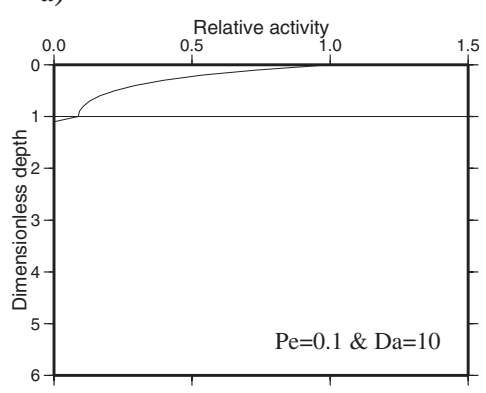

b)

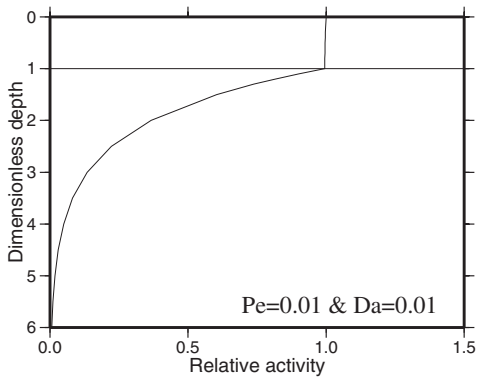

c)

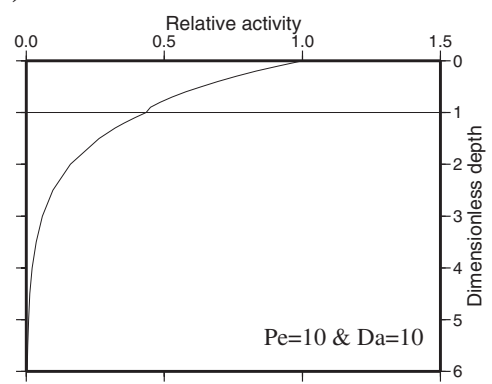

d)

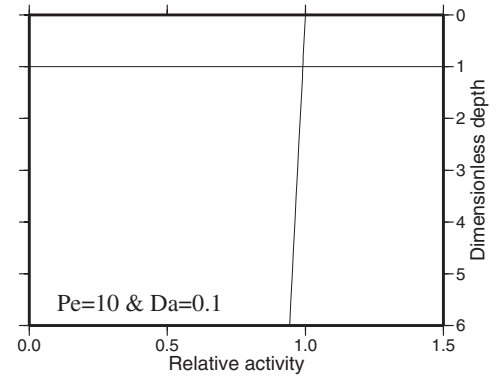

Figure 3. Samples of modeled steady-state depth profiles of ${ }^{210} \mathrm{~Pb}$ for different values of $\mathrm{Pe}$ and Da. (a), (b) , (c) and (d) profiles from the sectors 1, 2, 3 and 4, respectively. See text for signification of these sectors. Horizontal line represents the base of the bioturbated layer. The diagenetic model is a simple two layers model: the upper layer is affected by biodiffusion and burial and the lower one by burial only. Biodiffusion coefficient, burial rate and porosity are assumed to be constant. In this simple case, an analytical solution exists for the diagenetic equation. Formulae are derived from the literature (e.g. Boudreau, 1997).

determinations (Fig. 2). Finally, in sector 4, burial overshadows biodiffusion which itself dominates decay. This sector is also characterized by any slope difference along the radioactive profile (Fig. 3d). Additional difficulties arise due to slope uncertainties because sediment is well mixed by biodiffusion and decay rate is too slow to constrain this transport process. Fortunately, any point from natural environments falls inside this problematic sector.

Age-dependent mixing process (Smith et al., 1993; Fornes et al., 2001) or decay period effect (Reed et al., 2006) can explain the distribution difference of the Pe and Da values obtained from ${ }^{234} \mathrm{Th}$ and ${ }^{210} \mathrm{~Pb}$. Figure 2 shows that decay rate effect dominates agedependent mixing on the Da distribution in natural sedimentary environments. Considering both the relationships proposed by Middelburg et al. (1997) that relate $\mathrm{Db}$ and w with water depth and a constant mixed-layer depth $(9.8 \mathrm{~cm})$ according to Boudreau (1998), the shallower sedimentary environments are located toward large values of Pe and small values of Da. Inversely, the deeper environments trend toward lower Pe and larger Da. 


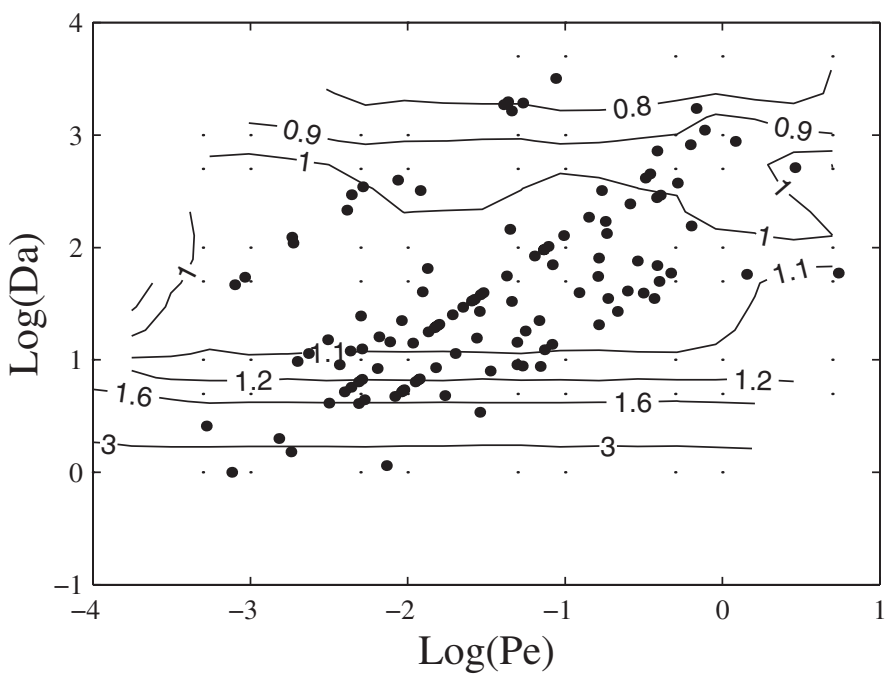

Figure 4. Sensitivity (S) of ${ }^{234}$ Th to seasonal biodiffusion as a function of the parameters Pe and Da. A perfect sensitivity is defined by $S=1$. Satisfactory sensitivity corresponds with $0.9<S<1.1$. Dots locate the selected numerical run for which a significant correlation exists between the depth along the profile and the logarithm of the dimensionless activity ( $>99$ percent significant level). Filled circles represent Pe and Da values for natural sedimentary environments (Table 2). The parameter $\gamma$ is equal to 0.095 .

Nevertheless, it is important to notice that the observed variability in Figure 2 is poorly controlled by a global relationship, but mainly by local variations of the $\mathrm{Db}$, w and $\mathrm{L}$ parameters. The Pe-Da diagram will be adopted in the next part of the paper to characterize sensitivity of the biodiffusion to seasonal bioturbation.

\section{Results}

According to the aims and objectives of this study, the period of sinusoidal oscillations is fixed to one year. As $\lambda$ is a constant, fixed value for each selected radioisotopes $\left({ }^{234} \mathrm{Th}\right.$, ${ }^{7} \mathrm{Be},{ }^{228} \mathrm{Th}$ and $\left.{ }^{210} \mathrm{~Pb}\right)$, the number of free parameters is finally reduced to three $(\mathrm{Pe}, \mathrm{Da}, \alpha)$. A sufficiently strong value for $\alpha$ ( 80 percent) is selected. This value is important to allow for sensitivity of biodiffusion within seasonal bioturbation.

For each numerical run characterized by a given couple of Pe and Da values, the sensitivity of the radioactive tracer is determined to the imposed seasonal biological mixing. The Pe and $\mathrm{Da}$ values are regularly selected inside the range of the compiled natural values (Table 2, Fig. 2). The transient solution of Eq. (4) is numerically solved and biodiffusion function computed from the slope of the radioactive profiles in a semilogarithm diagram (Eq. 9). The main tests allow the computation of the biodiffusion coefficient through the classical process because the shape of the radionuclide profile is very close to the exponential one which constitutes the solution of the steady-state 


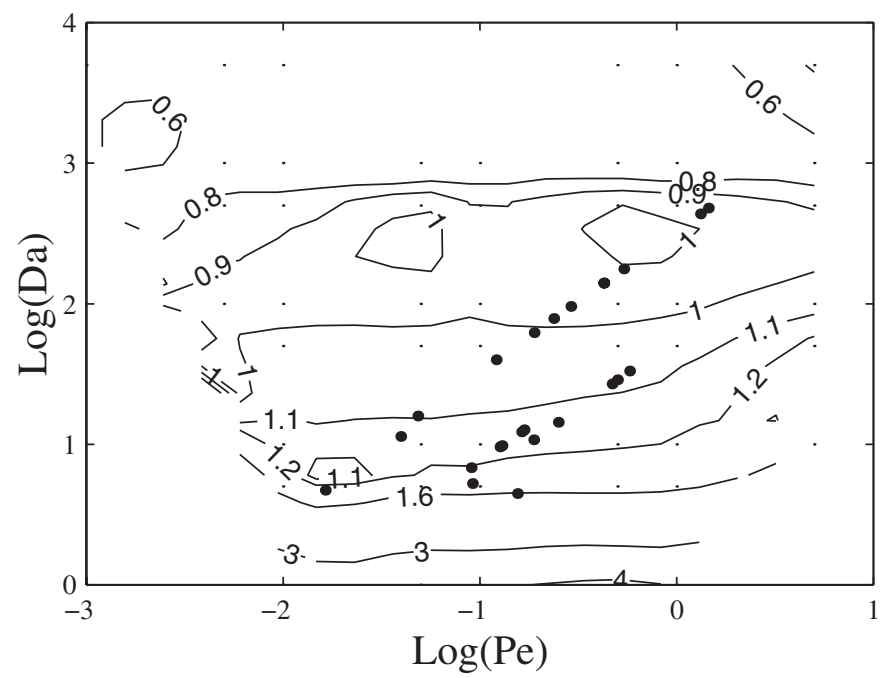

Figure 5. Sensitivity (S) of ${ }^{7}$ Be to seasonal bioturbation as a function of Pe and Da parameters. Same graphical codes as in Figure 4. $\gamma=0.211$.

equation. Then, the apparent amplitude of the biodiffusion function is characterized and compared to the actual one initially introduced in the transient model to compute the sensitivity of the radionuclide. Using Matlab ${ }^{\circledR}$ routines, a regular grid of sensitivity is interpolated from the (Pe, Da, S) points and then contours of equal value are drawn.

\section{a. Sensitivity of ${ }^{224}$ Th and ${ }^{7}$ Be to seasonal bioturbation}

The first simulation investigates the sensitivity of short-lived radioisotopes to seasonal biological activity. Two natural tracers are included in this category: ${ }^{234} \mathrm{Th}$ and ${ }^{7} \mathrm{Be}$. Corresponding pulses $(\gamma)$ are equal to 0.095 and 0.211 , respectively, which implies that decay time scale remains dominant over seasonal time scale. Due to the small penetration of ${ }^{234} \mathrm{Th}$ and ${ }^{7} \mathrm{Be}$ in the sediment, apparent biodiffusion function is then computed along a depth interval comprised between the first quarter and the first tenth of the mixed-layer depth. Sensitivity of ${ }^{234}$ Th to seasonal bioturbation varies between 0.63 and 3.93 (Fig. 4). For Pe lower than 1, lines of equal values of sensitivity are parallel to the Pe axis. So, sensitivity appears essentially to be dependent on the Da parameter in marine sediments dominated by bioturbation. For Pe greater than 1, sensitivity depends on both Pe and Da values. Satisfactory sensitivity, that can be defined as $S$ inside the 0.9 and 1.1 range, occurs in a large domain included between the lines $\mathrm{Da}=10$ and $\mathrm{Da}=1000$. For ${ }^{7} \mathrm{Be}$, sensitivity values are included inside a more extended range comprised between 0.38 and 4.15 and also depend on the Da parameter (Fig. 5). The satisfactory sensitivity domain is observed between the line $\mathrm{Da}=10$ and $\mathrm{Da}=50$ and is more restricted than for ${ }^{234} \mathrm{Th}$. 


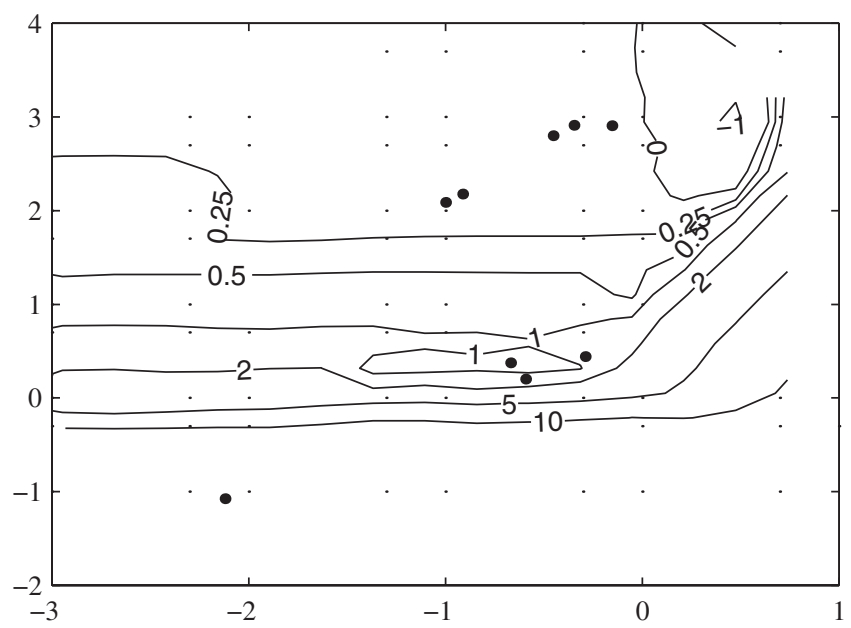

Figure 6. Sensitivity (S) of ${ }^{228} \mathrm{Th}$ to seasonal bioturbation as a function of Pe and Da parameters.

Same graphical codes as in Figure 4. $\gamma=2.74$.

\section{b. Sensitivity of ${ }^{228}$ Th and ${ }^{210} \mathrm{~Pb}$ to seasonal bioturbation}

Pulse values are equal to 2.74 and 31.74 , respectively. In this case, decay time is larger than seasonal time scale. Sensitivity ranges between 0.02 and 43.16 for ${ }^{228} \mathrm{Th}$ (Fig. 6) and between 0.0071 and 51 for ${ }^{210} \mathrm{~Pb}$ (Fig. 7). Pe parameter plays a minor role on the sensitivity of biodiffusion function within the domain defined by Pe lower than 1 . The domains

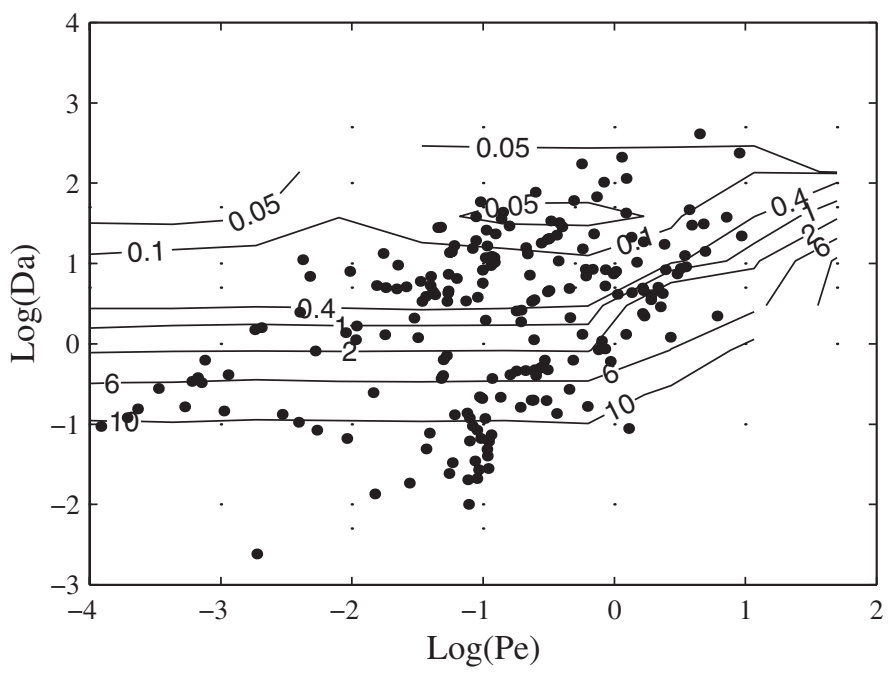

Figure 7. Sensitivity (S) of ${ }^{210} \mathrm{~Pb}$ to seasonal bioturbation as a function of Pe and Da parameters.

Same graphical codes as in Figure 4. $\gamma=31.74$. 
associated with underestimated or overestimated biodiffusion intensity dominate the diagrams. This result is directly related to the large pulse value associated with these two tracers. As expected, these tracers are clearly inappropriate for modeling seasonal biological activity in marine sediments. This result is valid whatever the selected Pe and Da values except for an extremely small and unexpected domain located in the vicinity of the domain defined by $\mathrm{S}=1$ (Fig. 7). This satisfactory domain is included between the lines $\log (\mathrm{Da})=0.7$ and $\log (\mathrm{Da})=0.8(5.01 \leq \mathrm{Da} \leq 6.31)$ for ${ }^{228} \mathrm{Th}$ and between the lines $\log (\mathrm{Da})=0.15$ and $\log (\mathrm{Da})=0.25(1.41 \leq \mathrm{Da} \leq 1.78)$ for ${ }^{210} \mathrm{~Pb}$. Satisfactory sensitivity domain of ${ }^{228} \mathrm{Th}$ is more extended than for ${ }^{210} \mathrm{~Pb}$. Figure 8 displays the results of a numerical simulation that illustrates the satisfactory sensitivity of the radionuclide ${ }^{210} \mathrm{~Pb}$ to seasonal mixing with this particular set of dimensionless parameters. The existence of a satisfactory sensitivity of the long-lived tracers to seasonal mixing is unexpected because ${ }^{210} \mathrm{~Pb}$ and ${ }^{228} \mathrm{Th}$ are associated with a decay time scale greater than the time scale of both biodiffusion and seasonal time scale. Nevertheless, the satisfactory domain exists and assumes the necessary transition between the two major domains of under and overestimated biodiffusion. For short-lived radionuclides, this transition dominates the Pe-Da diagram whereas for long-lived radionuclides it is reduced. The greater the radionuclide pulse, the more this transition is reduced. Three sediment cores, for which a complete description of the mixing parameters exists, falls inside the satisfactory sensitivity window of ${ }^{210} \mathrm{~Pb}$ : cores $183 \mathrm{KG}$ and $215 \mathrm{KG}$ from Peru Basin (Suckow et al., 2001) and core KTB14

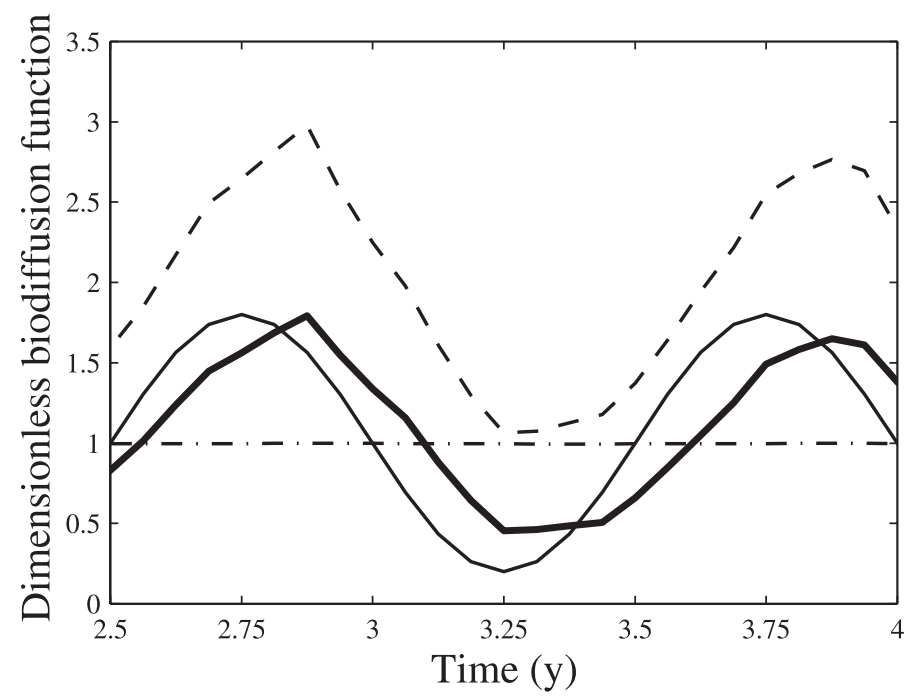

Figure 8. Sensitivity of ${ }^{210} \mathrm{~Pb}$ to seasonal biological mixing. The fine line represents the expected variations of the biodiffusion function initially introduced inside the transient model. Bold line is the apparent biodiffusion function calculated from the classical procedure employed on the transient profiles. Model parameters are $\mathrm{Pe}=0.1, \mathrm{Da}=1.35, \alpha=80$ percent. For comparison, the dashed line corresponds with a Da value of 1 and the dot-dashed line with a Da value of 100 . 
from the northeast tropical Atlantic (Legeleux et al., 1994). Other sediment cores are in close approximation: core KTB11 (Legeleux et al., 1994), cores Puget Sound E\#5 and 89 (Carpenter et al., 1985), core Mid Atlantic Bight station 3 (Tanaka et al., 1991) and core OMEX D8609 (van Weering et al., 1998).

\section{Discussion}

\section{a. Short-lived radionuclides sensitivity to bioturbation}

Reed et al. (2006) employed a lattice-automaton model of bioturbation to derive two estimates of the mixing intensity: a radionuclide-derived $\mathrm{Db}$ obtained by the standard biodiffusion model and a particle-tracking Db directly derived from the statistics of the particle movements. With a particular set of parameters, they showed that the two derived $\mathrm{Db}$ can be significantly different for short-lived radionuclides. The $\mathrm{Db}$ derived from short-lived tracers was systematically overestimated compared to the long-lived ones. They concluded that short-lived radionuclides are not appropriate to quantify mixing intensity. Additional investigations with the lattice automaton model are still needed to definitively exclude short-lived radionuclides:

First, the typical marine settings chosen by Reed et al. (2006) are not so typical. The selected sedimentary environments were characterized by an anomalously large $\mathrm{Da}=$ $\lambda \mathrm{L}^{2} / \mathrm{Db}$ value included between $10^{3}$ and $10^{5}$. These values are rarely observed in natural sedimentary environments (Fig. 4) even if an error of one or two order is affected to $\mathrm{Db}$, as suggested by these authors. In this case, the tracer decay is too fast compared to the biodiffusion process.

Second, Reed et al. (2006, Fig. 2) showed that the sensitivity of radionuclides to mixing intensity is improved when the half-life of the radionuclide increases. For coastal parameter sets, for example, the error between the particle-derived and the tracer-derived biodiffusion coefficients vanishes when the radionuclide half-life reaches $0.5 \mathrm{y}^{-1}$. They concluded that the short-lived radionuclides are not suitable to correctly quantify bioturbation intensity. Correlatively, the Da parameter decreases from the initial value of $2.10^{3}$ to the final value of 125 where the $\mathrm{Db}$ error becomes negligible. Additional tests with lattice automaton model of bioturbation are needed concerning the different parameters that control the system because the error on $\mathrm{Db}$ is clearly dependent on the three parameters $\lambda$, $\mathrm{Db}$ and $\mathrm{L}$ and not only on $\lambda$ : The Db error depends on the competition between the bioturbation intensity and the tracer decay that can be quantified through the $\mathrm{Da}=\lambda \mathrm{L}^{2} / \mathrm{Db}$ parameter. Reed et al. (2006) explored the influence of $\lambda$ on Db error, other choices exist that give satisfactory $\mathrm{Db}$ values, and especially with the short-lived radionuclides: for example, if bioturbation in the sediment is fixed to a greater value, the Da value can reach the boundary value of 125 and, in this case, the error on $\mathrm{Db}$ finally disappears. Increasing sediment mixing improves the sensitivity of the short-lived tracer to bioturbation before decaying. This new situation gives a parameters set compatible with the Da range observed in our compilation (Fig. 4). The third possible track to reduce the Db error consists in decreasing the mixed-layer depth. 
This analysis is valid whatever the considered short-lived radionuclide and can be applied to both slope and abyssal environments. In practice, biodiffusion analogy constitutes a satisfactory hypothesis for quantifying sediment mixing even if biological mixing violates the mathematical assumptions of biodiffusion. Short-lived radionuclides are devoted to quantify biological activity for natural environments characterized by a $\mathrm{Da}$ parameter lower than $10^{2}$. This result validates $75 \%$ and $79 \%$ of the compiled ${ }^{234} \mathrm{Th}-\mathrm{Db}$ and ${ }^{7} \mathrm{Be}-\mathrm{Db}$, respectively. Meysman et al. (2003) used the term 'biodiffusion paradox' to qualify this apparent contradiction between theory and practice. The best way to resolve this contradiction is to suppose that the complex mathematical formalism associated with biological mixing in marine sediment possesses a solution that clearly mimics the profile generated by the biodiffusion analogy. Correlatively, these results highlight the pertinence of the sensitivity study of short-lived radionuclides to seasonal bioturbation, especially in coastal systems where usually ${ }^{210} \mathrm{~Pb}$ presents a mixed layer and is not appropriate to such determination.

\section{b. Short-lived radionuclides sensitivity to seasonal biological mixing}

The domain of ${ }^{234}$ Th sensitivity encompasses most of marine surface sediments (Fig. 4). The steady state assumption assumed to compute the biodiffusion coefficient can therefore be extended to the seasonal regime imposed on the system. ${ }^{234} \mathrm{Th}$ is then adapted to follow strong seasonal variations of biological mixing. Among natural radionuclides, ${ }^{234} \mathrm{Th}$ constitutes the more sensible radioisotope able to follow seasonal bioturbation. Its rapid decay rate allows rapid adjustments of the radioactive profiles to seasonal bioturbation variations. For example, the tests reveal that the amplitude of the time variations of the biodiffusion coefficient is perfectly constrained with ${ }^{234}$ Th during the PULSE study (Gerino et al., 1998). This result supports a few exceptions and some marine sedimentary environments are clearly excluded from the satisfactory sensitivity domain. They correspond with a Da parameter greater than 1000 or lower than 10 . The marine environments associated with $\mathrm{Da}$ greater than 1000 underestimate the seasonal variations of $\mathrm{Db}$. Some examples of such environments have been revealed by the data compilation: they are characterized by either a small biological activity (e.g. cores MC19, MC66 and MC71 from Pope et al., 1996 or core PE138-99-1 from Schmidt et al., 2002) or a large mixed-layer depth (e.g. $\mathrm{L}=41 \mathrm{~cm}$ for the core 6 from Boer et al., 2006). This configuration of transport parameters limits the tracer penetration and correlatively the opportunity to constrain seasonal biological activity.

Marine environments associated with a Da parameter lower than 10 overestimate the sensitivity of the biodiffusion coefficient to seasonal biological activity. Such environments are generally characterized by either a Db value higher than $40 \mathrm{~cm}^{2} \mathrm{y}^{-1}$ (e.g. core PULSE 1 from Gerino et al., 1998 and core 1777 from Smith et al., 1993) or a mixed-layer depth lower than $3 \mathrm{~cm}$ (e.g. cores C4 from Schmidt et al., 2007). The decay time scale becomes insufficient in relation to the biodiffusion time scale to allow correct discrimination between the seasonal variations of the biological mixing. The mixed layer is saturated 
by the radionuclides. The slope of the radionuclide profile converges to zero and the $\mathrm{Db}$ value converges to infinity (Eq. 9). The radionuclide profile adopts a conservative shape when biodiffusion dominates decay. The seasonal oscillations are then completely hidden. In some cases, physical reworking associated for example to storms (Gerino et al., 1998), can significantly affect the profile shape and correlatively explain the strong observed biological mixing. The question that remains posed by this study concerns the reliability of the $\mathrm{Db}$ value, determined by field data analyses, to the actual biological activity intensity in the case of environments dominated by biodiffusion upon decay.

We can reduce the domain of satisfactory sensitivity to seasonal bioturbation to the domain for which the tracer-derived $\mathrm{Db}$ does not overestimate the bioturbation activity (Reed et al., 2006). With this consideration, the satisfactory range for ${ }^{234} \mathrm{Th}$ to seasonal mixing sensitivity is included between the Da range of 10 and 125. This domain encompasses most of the natural sediments (Fig. 4).

The domain of satisfactory seasonal sensitivity is slightly more restricted for ${ }^{7} \mathrm{Be}$ than for ${ }^{234} \mathrm{Th}$. The smaller the pulse $\gamma$, the more the domain of satisfactory sensitivity of radionuclide is extended. The majority of natural environments fall inside this domain of perfect sensitivity. The small number of cores, where ${ }^{7} \mathrm{Be}$ have been measured, limits the discussion concerning the natural marine environments for which this tracer is not well adapted to constrain the seasonal variations of the biological mixing. The discussion previously developed and concerning ${ }^{234} \mathrm{Th}$ can be extended to ${ }^{7} \mathrm{Be}$, but until now no marine environments, characterized by field analyses, correspond with underestimated seasonal biodiffusion amplitude (Fig. 5). Some natural marine environments fall inside the domain with overestimated seasonal oscillations. Biodiffusion dominates radionuclide decay and the seasonal variations of the biodiffusion are not correctly constrained by ${ }^{7} \mathrm{Be}$.

${ }^{234} \mathrm{Th}$ and ${ }^{7} \mathrm{Be}$ are satisfactory for the great majority of studied marine environments. The classical procedure followed to compute $\mathrm{Db}$ is adapted even in the case of the transient regime associated with the seasonal bioturbation. Based on the steady-state assumption, the classical method to compute $\mathrm{Db}$ is valid in cases of seasonal biological mixing. It appears more robust to seasonal variations of biodiffusion than to variations of imposed flux of the radionuclide through the sediment-water interface (Lecroart et al., 2007). Such a simple model offers sensitivity quantification for seasonal biodiffusion that can be used to correct the apparent amplitude of seasonal biological activity determined by field analyses. This approach could be applied to more complicated environments with some model adjustments.

\section{c. Long-lived radionuclides sensitivity to seasonal biological mixing}

The previous discussion concerning the origin of the imperfect seasonal sensitivity of the short-lived radionuclides can be extended to the long-lived ones. The incorrect sensitivity of these radionuclides was qualitatively expected from a simple time-scale consideration. The important result of this study is to reveal the presence of a small window in which seasonal biological activity can be detected from these radionuclides. 
This window is extremely restricted and its position depends on the selected radioactive tracer (Figs. 6 and 7). When a marine environment meets these transport characteristics, ${ }^{210} \mathrm{~Pb}$ can be a useful radionuclide to constrain seasonal mixing. Without competing ${ }^{234} \mathrm{Th}$ that constitutes the more adapted tracer, ${ }^{210} \mathrm{~Pb}$ has the advantage of a longer half-life, which allows measurements to be obtained after several years. A few natural environments fall inside this satisfactory window (Figs. 7 and 8). They are associated with a special combination of $\mathrm{Db}$ and $\mathrm{L}$ mixing parameters: Generally, they correspond with marine environments with moderate mixing affecting a deep mixed layer.

The question that can be asked now is to identify the period of biological activity that can be perfectly followed by the long-lived radioisotopes. Assuming that this period corresponds with a $\gamma$ value lower than 0.1 then this implies that the selected oscillation period must be larger than 3225 years for ${ }^{210} \mathrm{~Pb}$ and 27 years for ${ }^{228} \mathrm{Th} .{ }^{210} \mathrm{~Pb}$ does not appear to be useful in detecting variations in biological activity in marine surface sediments, except for a small window of correct sensitivity. However, ${ }^{228} \mathrm{Th}$ is perfectly adapted to detect variations of the biological activity related to imprint of human activity on marine sediments at a ten-year time scale.

\section{Conclusion}

The biodiffusion coefficient is the most commonly used parameter to constrain biological activity in marine sediments. Bioturbation characterization is important because this transport process is dominant in marine sediments and plays a major role in flux determination through sediment-water interface. Different radionuclides are available to compute $\mathrm{Db}$ from depth-activity profiles. This method is based on the basic steady-state assumption, but transient regimes are the rule in marine sediments, especially at the seasonal time scale and for coastal to shelf environments.

For most of the sedimentary settings, the short-lived radionuclides are suitable to quantify biological activity. Based on a new global compilation of radionuclide data and on previously published modeling results, we show that short-live radionuclides are perfectly devoted to quantify biological mixing for sediments associated with $\lambda \mathrm{L}^{2} / \mathrm{Db}$ lower than $125.75 \%$ of the ${ }^{234} \mathrm{Th}$-derived $\mathrm{Db}$, and $79 \%$ of the ${ }^{7} \mathrm{Be}$-derived $\mathrm{Db}$ are concerned by this result.

This study presents extensive sensitivity tests of Db calculation to seasonal mixing and quantitatively reveals that ${ }^{234} \mathrm{Th}$ constitutes the more sensitive tracer to detect seasonal biological mixing. In this case, the steady-state assumption remains valid and applicable for most of natural marine environments. This conclusion can also be extended to ${ }^{7} \mathrm{Be}$. However, these short-lived radionuclides are not always perfectly reliable for detecting seasonal biological mixing. In some marine environments, defined by particular values of the Da parameter, they incorrectly detect seasonal mixing amplitude. In these cases, the apparent seasonal variations of the biological activity can be corrected with the sensitivity parameter constrained by our study. The major parameter that determines the radionuclide choice is the dimensionless pulse that defines the relative importance of decay time scale 
relative to seasonal time scale. The pulse controls the relative extension of the domain for satisfactory sensitivity. With these considerations, long-lived radiotracers are not adapted to follow seasonal mixing processes in marine surface sediments. They are more adapted to detect biological mixing at a longer time scale, except for a specific domain which displays a satisfactory sensitivity to seasonal mixing. Marine environment characterized by moderate biological mixing and deep mixed-layer are concerned by this unexpected conclusion. In that case, ${ }^{210} \mathrm{~Pb}$ can be perfectly adapted to follow seasonal change in biological activity in marine sediment.

Acknowledgments. The compilation of transports parameters and the numerical report generated by COMSOL Multiphysics ${ }^{\circledR}$ are available upon simple request to the authors. We thank H. de Stigter for unpublished data from OMEX project and R. Wakefield for polishing of the English. GMT software (Wessel and Smith, 1998) was used to create location maps. This study was funded by the French Minister of Research (ACI JC ARTTE project) and by the National Program of Coastal Environments (BENTIDAL and MICROBENT projects). The authors thank the three reviewers for their helpful comments. This is an EPOC contribution 1615.

\section{REFERENCES}

Aller, R. C. 1982. The effects of macrobenthos on chemical properties of marine sediment and overlying water, in Animal-Sediment Relations, P. L. McCall and M. J. S. Tevesz, eds., Plenum, 53-102.

Aller, R. C., L. K. Benninger and J. K. Cochran. 1980. Tracking particle-associated processes in nearshore environments by use of ${ }^{234} \mathrm{Th} /{ }^{238} \mathrm{U}$ disequilibrium. Earth Planet. Sci. Lett., 47, 161-175.

Aller, R. C. and J. K. Cochran. 1976. ${ }^{234} \mathrm{Th} /{ }^{238} \mathrm{U}$ disequilibrium in near-shore sediment: Particle reworking and diagenetic time scales. Earth Planet. Sci. Lett., 29, 37-50.

Aller, R. C. and D. J. DeMaster. 1984. Estimates of particule flux and reworking at the deep-sea floor using ${ }^{234} \mathrm{Th} /{ }^{238} \mathrm{U}$ disequilibrium. Earth Planet. Sci. Lett., 67, 308-318.

Alperin, M. J., I. B. Suayah, L. K. Benninger and C. S. Martens. 2002. Modern organic carbon burial fluxes, recent sedimentation rates, and particle mixing rates from the upper continental slope near Cape Hatteras, North Carolina (USA). Deep-Sea Res. II, 49, 4645-4665.

Anderson, R. F., R. F. Bopp, K. O. Buesseler and P. E. Biscaye. 1988. Mixing of particles and organic constituents in sediments from the continental shelf and slope off Cape Cod: SEEP-I results. Cont. Shelf Res., 8, 925-946.

Benninger, L. K., R. C. Aller, J. K. Cochran and K. K. Turekian. 1979. Effects of biological sediment mixing on the ${ }^{210} \mathrm{~Pb}$ chronology and trace metal distribution in a Long Island Sound sediment core. Earth Planet. Sci. Lett., 43, 241-259.

Bentley, S. J. and C. A. Nittrouer. 2003. Emplacement, modification, and preservation of event strata on a flood-dominated continental shelf: Eel shelf, Northern California. Cont. Shelf Res., 23, 1465-1493.

Berg, P., S. Rysgaard, P. Funch and M. K. Sejr. 2001. Effects of bioturbation on solutes and solids in marine sediments. Aq. Micro. Ecol., 26, 81-94.

Berner, R. A. 1980. Early Diagenesis, A Theoretical Approach, Princeton University Press, 241 pp. Boer, W., G. D. van den Bergh, H. de Haas, H. C. de Stigter, R. Gieles and T. C. E. van Weering. 2006. Validation of accumulation rates in Teluk Banten (Indonesia) from commonly applied ${ }^{210} \mathrm{~Pb}$ models, using the 1883 Krakatau tephra as time marker. Mar. Geol., 227, 263-277.

Bosworth, W. S. and L. J. Thibodeaux. 1990. Bioturbation: A facilitator of contaminant transport in bed sediment. Env. Progr., 9, 211-217. 
Boudreau, B. P. 1986a. Mathematics of tracer mixing in sediments: I. Spatially-dependent, diffusive mixing. Am. J. Sci., 286, 161-198.

— 1986b. Mathematics of tracer mixing in sediments: II. Nonlocal mixing and biological conveyor-belt phenomena. Am. J. Sci., 286, 199-238.

1994. Is burial velocity a master parameter for bioturbation? Geochim. Cosmochim. Acta, 58, 1243-1249.

1997. Diagenetic models and their implementation: modeling, transport and reactions in aquatic sediments. Springer Verlag, 414 pp.

1998. Mean mixed depth of sediments: the wherefore and the why. Limnol. Oceanogr., 43, 524-526.

Brand, T. and G. Shimmield. 1991. The use of ${ }^{210} \mathrm{~Pb}$ as an indicator of biological processes affecting the flux and sediments geochemistry of organic carbon in the NE Atlantic, in Radionuclides in the Study of Marine Processes, P. J. Kershaw and D. S. Woodhead, eds., Elsevier, 222-233.

Carpenter, R., M. L. Peterson and J. T. Bennett. 1985. ${ }^{210} \mathrm{~Pb}$-derived sediment accumulation and mixing rates for the greater Puget Sound region. Mar. Geol., 64, 291-312.

Chaillou G., P. Anschutz, G. Lavaux, J. Schafer and G. Blanc. 2002. The distribution of Mo, U and $\mathrm{Cd}$ in relation to major redox species in muddy sediments of the Bay of Biscay, Mar. Chem., 80 , 41-59.

Cochran, J. K. 1985. Particle mixing rates in sediments of the eastern equatorial Pacific: Evidence from ${ }^{210} \mathrm{~Pb},{ }^{239,240} \mathrm{Pu}$ and ${ }^{137} \mathrm{Cs}$ distributions at MANOP sites. Geochim. Cosmochim. Acta, 49, 1195-1210.

Cochran, J. K., T. McKibbin-Vaughan, M. M. Dornblaser, D. Hirschberg, H. D. Livingston and K. O. Buesseler. 1990. ${ }^{210} \mathrm{~Pb}$ scavenging in the North Atlantic and North Pacific Oceans. Earth Planet. Sci. Lett., 97, 332-352.

Crusius, J. and T. C. Kenna. 2007. Ensuring confidence in raionuclide-based sediment chronologies and bioturbation rates. Estuar. Coast. Shelf Sci., 71, 537-544.

DeMaster, D. J. and J. K. Cochran. 1982. Particle mixing rates in deep-sea sediments determined from excess ${ }^{210} \mathrm{~Pb}$ and ${ }^{32} \mathrm{Si}$ profiles. Earth Planet. Sci. Lett., 61, 257-271.

DeMaster, D. J., R. H. Pope, L. A. Levin and N. E. Blair. 1994. Biological mixing intensity and rates of organic carbon accumulation in North Carolina slope sediments. Deep-Sea Res. II, 41, 735-753.

Fornes, W. L., D. J. DeMaster and C. R. Smith. 2001. A particle introduction experiment in Santa Catalina Basin sediments: Testing the age-dependent mixing hypothesis. J. Mar. Res., 59, 97-112.

Gerino, M., R. C. Aller, C. Lee, J. K. Cochran, J. Y. Aller, M. A. Green and D. Hirschberg. 1998. Comparison of different tracers and methods used to quantify bioturbation during a spring bloom: 234-Thorium, luminophores and chlorophyll $a$. Estuar., Coast. Shelf Sci., 46, 531-547.

Goldberg, E. D. and M. Koide. 1962. Geochronological studies of deep sea sediments by the ionium/thorium method. Geochim. Cosmochim. Acta, 26, 417-450.

Green, M. A., R. C. Aller, J. K. Cochran, C. Lee and J. Y. Aller. 2002. Bioturbation in shelf/slope sediments off Cape Hatteras, North Carolina: the use of ${ }^{234} \mathrm{Th}$, Chl- $a$ and $\mathrm{Br}^{-}$to evaluate rates of particle and solute transport. Deep-Sea Res. II, 49, 4627-4644.

Guinasso, N. L. and D. R. Schink. 1975. Quantitative estimates of biological mixing in abyssal sediments. J. Geophys. Res., 80, 3032-3043.

Henderson, G. M., F. N. Lindsay and N. C. Slowey. 1999. Variation in bioturbation with water depth on marine slopes: a study on the Little Bahamas Bank. Mar. Geol., 160, 105-118.

Jaeger, J. M. and C. A. Nittrouer. 2006. A quantitative examination of modern sedimentary lithofacies fromation on the glacially influenced Gulf of Alaska continental shelf. Cont. Shelf Res., 26, 2178-2204.

Kershaw, P. J. 1985. ${ }^{14} \mathrm{C}$ and ${ }^{210} \mathrm{~Pb}$ in NE Atlantic sediments: Evidence of biological reworking in the context of radioactive waste disposal. J. Env. Radio., 2, 115-134. 
Kim, K. H. and W. C. Burnett. 1988. Accumulation and biological mixing of Peru margin sediments. Mar. Geol., 80, 181-194.

Krishnaswami, S., L. K. Benninger, R. C. Aller and K. L. Von Damm. 1980. Atmosphericallyderived radionuclides as tracers of sediment mixing and accumulation in near-shore marine and lake sediments: evidence from ${ }^{7} \mathrm{Be},{ }^{210} \mathrm{~Pb}$, and ${ }^{239,240} \mathrm{Pu}$. Earth Planet. Sci. Lett., 47, 307-318.

Kuehl, S. A., T. J. Fuglseth and R. C. Thunell. 1993. Sediment mixing and accumulation rates in the Sulu and South China Seas: Implications for organic carbon preservation in deep-sea environments. Mar. Geol., 111, 15-35.

Lecroart, P., S. Schmidt and J. M. Jouanneau. 2007. Numerical estimation of the error of the biodiffusion coefficient in coastal sediments. Estuar. Coast. Shelf Sci., 72, 543-552. .

Legeleux, F., J. L. Reyss and S. Schmidt. 1994. Particle mixing rates in sediments of the northeast tropical Atlantic: evidence from ${ }^{210} \mathrm{~Pb}$ xs $,{ }^{137} \mathrm{Cs},{ }^{228} \mathrm{Th}_{\mathrm{xs}}$ and ${ }^{234} \mathrm{Th}_{\mathrm{xs}}$. Earth Planet. Sci. Lett., 128, 545-562.

Li, W. Q., N. L. Guinasso, K. H. Cole, M. D. Richardson, J. W. Johnson and D. R. Schink. 1985. Radionuclides as indicators of sedimentary processes in abyssal Caribbean sediments. Mar. Geol., 68, 187-204.

Lynch, D. R. and C. B. Officer. 1984. Nonlinear parameter estimation for sediment cores. Chem. Geol., 44, 203-225.

McManus, J., D. E. Hammond, W. M. Berelson, T. E. Kilgore, D. J. DeMaster, O. G. Ragueneau and R. W. Collier. 1995. Early diagenesis of biogenic opal: dissolution rates, kinetics and paleoceanographic implications. Deep-Sea Res. II, 42, 871-903.

Martin, W. R. and M. L. Bender. 1988. The variability of benthic fluxes and sedimentary remineralization rates in response to seasonally variable organic carbon rain rates in the deep sea: a modeling study. Am. J. Sci., 288, 561-574.

Masqué, P., E. Isla, J. A. Sanchez-Cabeza, A. Palanques, J. M. Bruach, P. Puig and J. Guillén. 2002. Sediment accumulation rates and carbon fluxes to bottom sediments at the Western Bransfield Strait (Antarctica). Deep-Sea Res. II, 49, 921-933.

Meysman, F. J. R., B. P. Boudreau and J. J. Middelburg. 2003. Relations between local, nonlocal, discrete and continuous models of bioturbation. J. Mar. Res., 61, 391-410.

Meysman, F. J. R., V. S. Malyuga, B. P. Boudreau and J. J. Middelburg. 2007. The influence of porosity gradients on mixing coefficients in sediments. Geochim. Cosmochim. Acta, 71, 961-973.

Middelburg, J. J., K. Soetaert and P. M. J. Herman. 1997. Empirical relationships for use in global diagenetic models. Deep Sea Res. I, 44, 327-344.

Mulsow, S., B. Boudreau and J. N. Smith. 1998. Bioturbation and porosity gradients. Limnol. Oceanogr., 43, 1-9.

Nittrouer, C. A., D. J. DeMaster, B. A. McKee, N. H. Cutshall and I. L. Larsen. 1983/1984. The effect of sediment mixing on $\mathrm{Pb}-210$ accumulation rates for the Washington continental shelf. Mar. Geol., 54, 201-221.

Nozaki, Y., J. K. Cochran and K. K. Turekian. 1977. Radiocarbon and ${ }^{210} \mathrm{~Pb}$ distribution in submersible-taken deep-sea cores from project FAMOUS. Earth Planet. Sci. Lett., 34, 167-173.

Peng, T. H., W. S. Broecker and W. H. Berger. 1979. Rates of benthic mixing in deep-sea sediments as determined by radioactive tracers. Quaternary Res., 11, 141-149.

Pope, R. H., D. J. Demaster, C. R. Smith and H. J. Seltman. 1996. Rapid bioturbation in equatorial Pacific sediments: evidence from excess ${ }^{234}$ Th measurements. Deep-Sea Res. II, 43, 1339-1364.

Reed, D. C., K. Huang, B. P. Boudreau and F. J. R. Meysman. 2006. Steady-state tracer dynamics in a lattice-automaton model of bioturbation. Geochim. et Cosmochim. Acta, 70, 5855-5867.

Rice, D. L. 1986. Early diagenesis in bioadvective sediments: Relationships between the diagenesis of beryllium-7, sediment reworking rates, and the abundance of conveyor-belt deposit-feeders. J. Mar. Res., 44, 149-184. 
Ruddiman, W. F. and L. K. Glover. 1972. Vertical mixing of ice-rafted volcanic ash in North Atlantic sediments. Geol. Soc. Am. Bull., 83, 2817-2836.

Sanchez-Cabeza, J. A., P. Masqué, I. Ani-Ragolta, J. Merino, M. Frignani, F. Alvisi, A. Palanques and P. Puig. 1999. Sediment accumulation rates in the southern Barcelona continental margin (NW Mediterranean Sea) derived from ${ }^{210} \mathrm{~Pb}$ and ${ }^{137} \mathrm{Cs}$ chronology. Prog. Oceanogr., 44, 313-332.

Santschi, P. H., Y.-H. Li, J. J. Bell, R. M. Trier and K. Kawtaluk. 1980. Pu in coastal marine environments. Earth Planet. Sci. Lett., 51, 248-265.

Sayles, F. L., W. R. Martin, Z. Case and R. F. Anderson. 2001. Benthic remineralization and burial of biogenic $\mathrm{SiO}_{2}, \mathrm{CaCO}_{3}$, organic carbon, and detrital material in the Southern Ocean along a transect at $170^{\circ}$ West. Deep-Sea Res. II, 48, 4323-4383.

Schink, D. R. and N. L. Guinasso. 1977. Effects of bioturbation on sediment-seawater interaction. Mar. Geol., 23, 133-154.

Schmidt, S., H. C. de Stigter and T. C. E. van Weering. 2001. Enhanced short term sediment deposition within the Nazaré Canyon, North-East Atlantic. Mar. Geol., 173, 55-67.

Schmidt, S., T. C. C. van Weering, J. L. Reyss and P. van Beek. 2002. Seasonal deposition and reworking at the sediment-water interface on the northwestern Iberian margin. Progr. Oceanogr., 52, 331-348.

Schmidt, S., J. M. Jouanneau, O. Weber, P. Lecroart, O. Radakovitch, F. Gilbert, D. Jezequel and C. Rabouille. 2007. Sedimentary processes in the Thau Lagoon (France): From seasonal to century time scales. Estuar., Coast. Shelf Sci., 72, 534-542.

Schmidt, S., De Deckker, P., Caradec, S., 2007. Modern sedimentation associated with the Murray Canyons Group offshore southern Australia. Earth Planet. Sci. Lett., (submitted).

Silverberg, N., H. V. Nguyen, G. Delibrias, M. Koide, B. Sundby, Y. Yokoyama and R. Chesselet. 1986. Radionuclide profiles, sedimentation rates and bioturbation in modern sediments of the Laurentian Trough, Gulf of St. Lawrence. Oceanol. Acta, 9, 285-290.

Smith, C. R., R. H. Pope, D. J. DeMaster and L. Magaard. 1993. Age-dependent mixing of deep-sea sediments. Geochim. Cosmochim. Acta, 57, 1473-1488.

Smith, C. R., L. A. Levin, D. J. Hoover, G. McMurtry and J. D. Gage. 2000. Variation in bioturbation across the oxygen minimum zone in the northwest Arabian Sea. Deep-Sea Res. II, 47, 227-257.

Smith, C. R. and C. Rabouille. 2002. What controls the mixed-layer depth in deep-sea sediments? The importance of POC flux. Limnol. Oceanogr., 47, 418-426.

Smoak, J. M. and S. R. Patchineelam. 1999. Sediment mixing and accumulation in a mangrove ecosystem: evidence from ${ }^{210} \mathrm{~Pb},{ }^{234} \mathrm{Th}$ and ${ }^{7} \mathrm{Be}$. Mangroves Salt Marshes, 3, 17-27.

Soetaert, K., P. M. J. Herman and J. J. Middelburg. 1996a. Dynamic response of deep-sea sediments to seasonal variations: A model. Limnol. Oceanogr., 41, 1651-1668.

Soetaert, K., P. M. J. Herman, J. J. Middelburg, C. Heip, H. S. de Stigter, T. C. E. van Weering, E. Epping and W. Helder. 1996b. Modeling ${ }^{210} \mathrm{~Pb}$-derived mixing activity in ocean margin sediments: Diffusive versus nonlocal mixing. J. Mar. Res., 54, 1207-1227.

Stordal, M. C., J. W. Johnson, N. L. Guinasso and D. R. Schink. 1985. Quantitative evaluation of bioturbation rates in deep ocean sediments. II. Comparison of rates determined by ${ }^{210} \mathrm{~Pb}$ and ${ }^{239,240}$ Pu. Mar. Chem., 17, 99-114.

Suckow, A., U. Treppke, M. H. Wiedicke and M. E. Weber. 2001. Bioturbation coefficients of deep-sea sediments from the Peru Basin determined by gamma spectrometry of ${ }^{210} \mathrm{~Pb}_{\text {exc }}$. Deep-Sea Res. II, 48, 3569-3592.

Sun, M.-Y., R. C. Aller and C. Lee. 1991. Early diagenesis of chlorophyll-a in Long Island Sound sediments: A measure of carbon flux and particle reworking. J. Mar. Res., 49, 379-401.

Sun, M.-Y., R. C. Aller and C. Lee. 1994. Spatial and temporal distributions of sedimentary chloropigments as indicators of benthic processes in Long Island Sound. J. Mar. Res., 52, 149-176. 
Tanaka, N., K. K. Turekian and D. M. Rye. 1991. The radiocarbon, ${ }^{13} \mathrm{C},{ }^{210} \mathrm{~Pb}$, and ${ }^{137} \mathrm{Cs}$ record in box cores from the continental margin of the Middle Atlantic Bight. Am. J. Sci., 291, 90-105.

Thomas, C. J., N. E. Blair, M. J. Alperin, D. J. DeMaster, R. A. Jahnke, C. S. Martens and L. Mayer. 2002. Organic carbon deposition on the North Carolina continental slope off Cape Hatteras (USA). Deep-Sea Res. II, 49, 4687-4709.

Thomson, J., S. Colley, R. Anderson, G. T. Cook and A. B. MacKenzie. $1993 .{ }^{210} \mathrm{~Pb}$ in the sediments and water column of the Northeast Atlantic from 47 to $59^{\circ} \mathrm{N}$ along $20^{\circ} \mathrm{W}$. Earth Planet. Sci. Lett., $115,75-87$.

Thomson, J., L. Brown, S. Nixon, G. T. Cook and A. B. MacKenzie. 2000. Bioturbation and Holocene sediment accumulation fluxes in the north-east Atlantic Ocean (Benthic Boundary Layer experiment sites). Mar. Geol., 169, 21-39.

Turnewitsch, R., U. Witte and G. Graf. 2000. Bioturbation in the abyssal Arabian Sea: Influence of fauna and food supply. Deep-Sea Res. II, 47, 2877-2911.

van Weering, T. C. E., I. N. McCave and I. R. Hall. 1998. Ocean Margin Exchange (OMEX I) benthic processes study. Prog. Oceanogr., 42, 1-4.

van Weering, T. C. E., H. C. de Stitger, W. Boer and H. de Haas. 2002. Recent sediment transport and accumulation on the NW Iberian margin. Prog. Oceanogr., 52, 349-371.

Wessel, P. and W. H. F. Smith. 1998. Improved version of the generic Mapping Tool released. EOS Trans. AGU, 79, 579.

Wheatcroft, R. A. 1990. Preservation potential of sedimentary event layers. Geology, 18, 843-845.

Yang, H.-S., Y. Nozaki, H. Sakai, Y. Nagaya and K. Nakamura. 1986. Natural and man-made radionuclide distributions in Northwest Pacific deep-sea sediments: rates of sedimentation, bioturbation and ${ }^{226}$ Ra migration. Geochem. J., 20, 29-40.

Received: 11 October, 2006; revised: 2 April, 2007. 